\title{
Practice on the Grouping Micro-Video Competition Teaching Mode in Large-Class Biochemistry Course
}

\author{
Genliang Li*, Anni Ni, Xiaomin Huang, Shubo Li, Song Nong \\ Youjiang Medical University for Nationalities \\ Baise City, Guangxi \\ ligenliang@163.com
}

\begin{abstract}
In order to find a teaching mode that can meet the needs of the teaching in large class, we integrate various theories and teaching methods, construct grouping micro-video competition teaching mode and implement it in the biochemistry course in 6 undergraduate classes of 2016 nursing major of Youjiang Medical University for Nationalities to test its application effect in large class. After surveying to one experimental class $(n=103)$ and 2 control classes $(n=210)$ in the form of questionnaire and analyzing the final examine scores of experimental and control contents, it is shown that students' average scores in experimental class in which the micro-video competition teaching mode is adopted and the scores of objective and subjective questions are significantly higher than those in controls $(P<0.05)$, while there is no significant difference in the scores of contents between experimental class and controls $(P>$ 0.05). In particular, there is a statistical difference in the scoring rate of objective questions between experimental content and control content in the experimental class $(P<0.05)$, while there is no significant difference in the scoring rate of subjective questions $(P>\mathbf{0 . 0 5})$. Students prefer to affirm the micro-video competition teaching mode $(P<0.05)$, while they are generally uncertain towards traditional lecturing teaching mode in questionnaire $(P<0.05)$. The research results show that the micro-video competition teaching mode has promoted students' memory and mastery on the experiment content. Especially, in the aspect of training students' comprehensive analysis and the ability to apply knowledge, the teaching effect of the mode is better that of traditional mode. It not only promotes the ability of students' comprehensive analysis and its application to the experiment content, but also the ability of their comprehensive analysis to other teaching content and relevant skills.
\end{abstract}

Keywords-grouping micro-video competition teaching mode, large-class teaching, biochemistry, ability of comprehensive analysis and application

\section{INTRODUCTION}

Grouping micro-video competition teaching mode is a set of new teaching mode that we constructed by integrating various theories and teaching methods, including in the team-learning mode, flipped classroom teaching mode, micro-lecture teaching mode and competition learning mode under the background of the popularity of mobile phone among college students, universality, convenience and popularity of micro-video ${ }^{[1-9]}$. It refers to the completion of the learning goals of specific unit under the guidance of the pyramid cognition theory, cooperative learning theory, and theory of multiple evaluation, through the division of groups and cooperation of members within each group to learn a small knowledge unit by the production of micro-video as the first carrier, diversified evaluation integrating intra-group evaluation, inter-group evaluation, teacher evaluation, in-classroom testing evaluation, and end-of-term testing evaluation as a means of regulation, "student-centered self-evaluation" as the second study carrier and joint participation in the extension of teaching content as the third study carrier ${ }^{[1]}$. This teaching mode is beneficial to the cultivation of all-round developing high-quality college students in the large-class biochemistry course. It is of great theoretical and practical significance to research in related field.

\section{METHOD}

\section{A. Research objects}

313 undergraduate students of 2016 nursing major from Youjiang Medical University for Nationalities are the research objects who are divided into three large classes composed of each two class from original 6 classes. Among them, we adopt the grouping micro-video competition teaching mode in some biochemistry courses in a large class $(n=103)$ as the experimental class. And traditional lecturing teaching mode is used in other contents as control content. The traditional teaching mode is also used in all biochemistry courses in other two large classes $(n=210)$ as the control classes.

\section{B. Implementation process}

The plan firstly includes the construction of large-class WeChat teaching platform for grouping students and the training of related skills in the process of the implementation of with grouping micro-video competition teaching mode. Secondly, students study independently before class, make micro video in each group, and mutually evaluate among members in each group, while teachers make micro video outlining difficult teaching points. Thirdly, it is the showing and evaluation of micro video and in-class test. Next, teachers will answer questions in classrooms and integrate and expand the knowledge and ability. Additionally, they will get extra scores to the students who perform well in class. After class, the interaction between teachers and students and among students can be carried out in the WeChat teaching platform and micro-video for learning difficulties will be released. Finally, it is the final general evaluation, commendation and distribution of certificates and prizes. 
The multiple evaluation in the implementation of the grouping micro-video competition teaching mode includes: (1) intra-group evaluation (10\%); (2) students' evaluation on micro-video (30\%); (3) teachers' evaluation on micro-video (10\%); (4) classroom test evaluation (10\%); (5) micro-video playback effect evaluation based on classroom test score (10\%); (6) teachers' classroom evaluation (extra scores); (7) evaluation in the final examination (20\%); (8) micro-video playback effect evaluation according to the final test score(10\%).

\section{Analysis of the learning effect of teaching content}

The rate of score is summed up by analyzing final examination paper influenced by the study effect of learning contents in order to evaluate the student's study effect.

\section{Questionnaires}

The questionnaire consists of 15 questions related to the teaching purpose and teaching effect, which are evaluated by students positively or negatively in 5 levels and compared with students' evaluation on traditional teaching mode. The 15 questions include: suitable for large-class teaching, innovation, conducive to promote a preview before class, to enhance students' team consciousness, students' self-study, active classroom atmosphere, to pay more attention in class, to access to learning resources, to improve students' ability to apply knowledge, to improve the students' interpersonal communication ability, to cultivate interest in learning, to communicate with each other in study, to strengthen theoretical knowledge, to inspire thinking ability, and to improve the ability of expression.

\section{E. Statistical analysis}

The analysis is carried out on the data through the function of statistical analysis of Excel software. Data is represented by $(\bar{x} \pm s)$. It first adopts double sample variance analysis ( $F$-test) to evaluate the homogeneity of variance of data, then the double tail critical $t$-test is carried out. Among them, $P<0.05$ is defined as significant difference among data.

\section{RESULT}

\section{A. Students' learning effect on theoretical knowledge}

From the analysis on students' study effect of theoretical knowledge and the scores of objective and subjective questions, it is shown that different teaching modes affect students' mastery of theoretical knowledge, and students' scores in the experimental class in which the with micro-video competition teaching mode is adopted are higher than those in control class in which the traditional lecturing teaching mode is used. Among them, there are significant differences on the experimental content between the scores of objective and subject questions of experimental and control class (the teaching mode with micro-video competition is used in experimental class whereas traditional teaching mode is used in control classes), while there are no statistical differences on control contents between these two classes (the teaching contents are imparted through traditional lecturing teaching mode both in experimental class and control classes) (TABLE I). In particular, there is a significant difference on the scoring rate of objective questions between experimental contents and control contents in the experimental class, while there is no significant difference in the scoring rate of subjective questions (TABLE II). The results show that the teaching effect of the micro-video competition teaching mode is obviously better than that of the traditional lecturing teaching mode in large-class teaching activities.

TABLE I. COMPARISON BETWEEN EXPERIMENTAL AND CONTROL CONTENTS IN DIFFERENT CLASSES

\begin{tabular}{|c|c|c|c|c|c|c|c|c|c|}
\hline & & \multicolumn{2}{|c|}{$\begin{array}{l}\text { Objective questions of } \\
\text { experimental contents }\end{array}$} & \multicolumn{2}{|c|}{$\begin{array}{l}\text { Objective questions of } \\
\text { comparative contents }\end{array}$} & \multicolumn{2}{|c|}{$\begin{array}{l}\text { Subjective questions of } \\
\text { experimental contents }\end{array}$} & \multicolumn{2}{|c|}{$\begin{array}{l}\text { Subjective questions of control } \\
\text { contents }\end{array}$} \\
\hline & & Experimental class & $\begin{array}{c}\text { Control } \\
\text { class }\end{array}$ & Experimental class & $\begin{array}{l}\text { Control } \\
\text { class }\end{array}$ & Experimental class & $\begin{array}{c}\text { Control } \\
\text { class }\end{array}$ & $\begin{array}{c}\text { Experimental } \\
\text { class }\end{array}$ & $\begin{array}{l}\text { Control } \\
\text { class }\end{array}$ \\
\hline \multirow{3}{*}{ Data } & $\overline{\bar{x}}$ & 81.31 & 69.12 & 72.79 & 75.25 & 72.06 & 52.33 & 61.65 & 51.20 \\
\hline & $s^{2}$ & 150.80 & 465.72 & 554.08 & 199.60 & 124.31 & 4.97 & 79.69 & 219.91 \\
\hline & $n$ & 20 & 20 & 40 & 40 & 3 & 3 & 4 & 4 \\
\hline \multirow{3}{*}{$\begin{array}{l}F- \\
\text { text }\end{array}$} & $d f$ & 19 & 19 & 39 & 39 & 2 & 2 & 3 & 3 \\
\hline & $F$ & \multicolumn{2}{|l|}{0.32} & \multicolumn{2}{|l|}{2.78} & \multicolumn{2}{|c|}{25.02} & \multicolumn{2}{|c|}{0.36} \\
\hline & $P$ & \multicolumn{2}{|l|}{0.01} & \multicolumn{2}{|l|}{0.00} & \multicolumn{2}{|c|}{0.04} & \multicolumn{2}{|c|}{0.21} \\
\hline \multirow{3}{*}{$\begin{array}{l}t- \\
\text { text }\end{array}$} & $d f$ & \multicolumn{2}{|l|}{30} & \multicolumn{2}{|c|}{64} & \multicolumn{2}{|c|}{2} & \multicolumn{2}{|c|}{6} \\
\hline & $t$ & \multicolumn{2}{|l|}{2.20} & \multicolumn{2}{|c|}{-0.57} & \multicolumn{2}{|c|}{3.00} & \multicolumn{2}{|c|}{1.21} \\
\hline & $P$ & \multicolumn{2}{|l|}{0.04} & \multicolumn{2}{|l|}{0.57} & \multicolumn{2}{|c|}{0.05} & \multicolumn{2}{|c|}{0.14} \\
\hline
\end{tabular}

TABLE II. COMPARISON OF EXPERIMENTAL AND CONTROL CONTENTS IN THE SAME CLASS

\begin{tabular}{|c|c|c|c|c|c|c|c|c|c|}
\hline & & \multicolumn{2}{|c|}{$\begin{array}{l}\text { Objective questions of } \\
\text { experimental class }\end{array}$} & \multicolumn{2}{|c|}{$\begin{array}{l}\text { Subjective questions of } \\
\text { experimental class }\end{array}$} & \multicolumn{2}{|c|}{$\begin{array}{l}\text { Objective questions of control } \\
\text { class }\end{array}$} & \multicolumn{2}{|c|}{$\begin{array}{l}\text { Subjective questions of control } \\
\text { class }\end{array}$} \\
\hline & & $\begin{array}{l}\text { Experimental } \\
\text { content }\end{array}$ & $\begin{array}{l}\text { Control } \\
\text { content }\end{array}$ & $\begin{array}{l}\text { Experimental } \\
\text { content }\end{array}$ & $\begin{array}{l}\text { Control } \\
\text { content }\end{array}$ & $\begin{array}{l}\text { Experimental } \\
\text { content }\end{array}$ & $\begin{array}{l}\text { Control } \\
\text { content }\end{array}$ & $\begin{array}{l}\text { Experimental } \\
\text { content }\end{array}$ & $\begin{array}{l}\text { Control } \\
\text { content }\end{array}$ \\
\hline \multirow{3}{*}{ Data } & $\overline{\mathrm{x}}$ & 81.31 & 72.79 & 72.06 & 61.65 & 69.12 & 75.25 & 52.33 & 51.20 \\
\hline & s2 & 150.80 & 554.08 & 124.31 & 79.69 & 465.72 & 199.61 & 4.97 & 219.91 \\
\hline & $\mathrm{n}$ & 20 & 40 & 3 & 4 & 20 & 40 & 3 & 4 \\
\hline \multirow{3}{*}{$\begin{array}{l}F- \\
\text { test }\end{array}$} & $\mathrm{df}$ & 19 & 39 & 2 & 3 & 19 & 39 & 2 & 3 \\
\hline & $\mathrm{F}$ & \multicolumn{2}{|c|}{0.27} & \multicolumn{2}{|c|}{1.56} & \multicolumn{2}{|c|}{2.33} & \multicolumn{2}{|c|}{0.02} \\
\hline & $\mathrm{P}$ & \multicolumn{2}{|c|}{0.00} & \multicolumn{2}{|c|}{0.34} & \multicolumn{2}{|c|}{0.01} & \multicolumn{2}{|c|}{0.02} \\
\hline \multirow{3}{*}{$\begin{array}{c}t- \\
\text { test }\end{array}$} & $\mathrm{df}$ & \multicolumn{2}{|c|}{58} & \multicolumn{2}{|c|}{5} & \multicolumn{2}{|c|}{27} & \multicolumn{2}{|c|}{3} \\
\hline & $\mathrm{t}$ & \multirow{2}{*}{\multicolumn{2}{|c|}{$\begin{array}{l}1.84 \\
0.07\end{array}$}} & \multicolumn{2}{|c|}{1.38} & \multicolumn{2}{|c|}{-1.15} & \multicolumn{2}{|c|}{0.15} \\
\hline & $\mathrm{P}$ & & & \multicolumn{2}{|c|}{0.23} & \multicolumn{2}{|c|}{0.26} & \multicolumn{2}{|c|}{0.89} \\
\hline
\end{tabular}




\section{B. Students' evaluation on teaching mode}

In order to make statistics on students' evaluation on the two teaching modes, we set up 15 questions in questionnaire, select 45 students from the experimental class for survey at random and ask them to evaluate each question in five levels, which are strongly agree, agree, uncertain, disagree and strongly disagree respectively. A total of 43 effective questionnaires are collected. According to the results of the analysis of the questionnaire, it is shown that students' evaluation on the grouping micro video competition teaching mode centers on the option of strong agreement $(P<0.05)$, and the evaluation on traditional lecturing teaching mode focuses on the option of uncertain $(P<0.05)$. There is no statistical difference on the evaluation of agreement of two kinds of teaching mode $(P>0.05)$, but few people disagree and strongly disagree the two teaching modes (TABLE III). There is a statistical difference in students' evaluation of the two teaching modes in terms of the options of the strongly-agreed and uncertain. Therefore, we further analyze the differences on the options of strongly-agreed and uncertain on the questions in questionnaire between the two teaching models. Results show that, in addition to two questions: "be suitable for large-class teaching" and "be conducive pay more attention on class" $(P>$ 0.05), students are inclined to the grouping micro-video competition teaching mode from their evaluation on other questions $(P<0.05)$, while they generally hold uncertain attitude toward traditional lecturing teaching mode $(P<0.05)$ except the question of "being capable of improving students' ability in using learnt knowledge" $(P>0.05)$ (Fig. 1), which indicates that students prefer the micro-video competition teaching mode, but they do not deny traditional teaching mode.

TABLE III. STUDENTS' GENERAL EVALUATION ON THE MICRO-VIDEO COMPETITION TEACHING MODE AND TRADITIONAL LECTURING TEACHING MODE

\begin{tabular}{|c|c|c|c|c|c|c|c|c|c|c|c|}
\hline & & \multicolumn{2}{|c|}{ Strongly agree } & \multicolumn{2}{|c|}{ Agree } & \multicolumn{2}{|c|}{ Uncertain } & \multicolumn{2}{|c|}{ Disagree } & \multicolumn{2}{|c|}{ Strongly disagree } \\
\hline & & 1 & 2 & 1 & 2 & 1 & 2 & 1 & 2 & 1 & 2 \\
\hline \multirow{3}{*}{ Data } & $\bar{x}$ & 18.07 & 4.53 & 13.87 & 11.47 & 7.20 & 19.267 & 0.87 & 1.533 & 0.33 & 1.33 \\
\hline & $s^{2}$ & 34.92 & 9.84 & 10.27 & 22.70 & 17.03 & 25.21 & 1.12 & 1.838 & 0.38 & 0.95 \\
\hline & $n$ & 15 & 15 & 15 & 15 & 15 & 15 & 15 & 15 & 15 & 15 \\
\hline \multirow{3}{*}{$\begin{array}{l}F- \\
\text { test }\end{array}$} & $d f$ & 14 & 14 & 14 & 14 & 14 & 14 & 14 & 14 & 14 & 14 \\
\hline & $F$ & \multicolumn{2}{|c|}{3.55} & \multicolumn{2}{|c|}{0.45} & \multicolumn{2}{|c|}{0.68} & \multicolumn{2}{|c|}{0.61} & \multicolumn{2}{|c|}{0.40} \\
\hline & $P$ & \multicolumn{2}{|c|}{0.01} & \multicolumn{2}{|c|}{0.08} & \multicolumn{2}{|c|}{0.24} & \multicolumn{2}{|c|}{0.18} & \multicolumn{2}{|c|}{0.05} \\
\hline \multirow{3}{*}{$\begin{array}{l}{ }^{t-} \\
\text { test }\end{array}$} & $d f$ & \multirow{2}{*}{\multicolumn{2}{|c|}{$\frac{14}{769}$}} & & $\begin{array}{c}14 \\
151\end{array}$ & & & & & & \\
\hline & $t$ & & & & & \multicolumn{2}{|c|}{-7.10} & \multicolumn{2}{|c|}{-1.54} & \multicolumn{2}{|c|}{-3.87} \\
\hline & $P$ & \multicolumn{2}{|c|}{0.00} & \multicolumn{2}{|c|}{0.15} & \multicolumn{2}{|c|}{0.00} & \multicolumn{2}{|c|}{0.15} & \multicolumn{2}{|c|}{0.00} \\
\hline
\end{tabular}

Note: 1. Grouping micro-video competition teaching mode, 2. Traditional lecture-based teaching mode

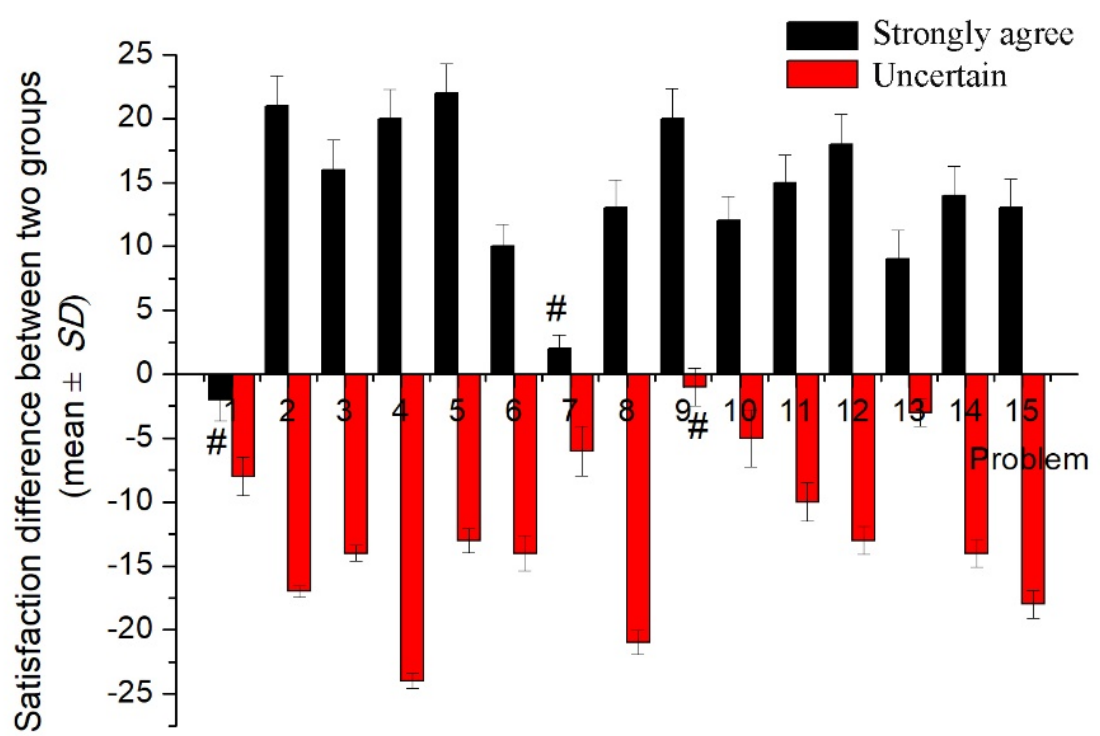

Fig. 1. Comparison between the micro-video competition teaching mode and the traditional lecturing teaching mode in terms of students' strong support and uncertainty for each questionnaire question

Note: 1 . be suitable for large-class teaching, 2. innovation, 3. conducive to promote a preview before class, 4 . conducive to enhance students' team consciousness, 5 . conducive to students' self-study, 6 . conducive to active classroom atmosphere, 7 . conducive to pay more attention in class, 8 . conducive to access to learning resources, 9 . conducive to improve students' ability to apply knowledge, 10 . conducive to improve the students' interpersonal communication ability, 11 . conducive to cultivate interest in learning, 12. conducive to communicate with each other in study, 13 . conducive to strengthen theoretical knowledge, 14 . conducive to inspire thinking ability, 15. conducive to improve the ability of expression. Compared with the traditional lecture-based teaching mode, there is no significant difference in micro-video competition teaching mode, 


\section{DISCUSSION}

Large-class teaching is the main teaching method for biochemistry course in colleges and universities. Large-class teaching has, to some extent, solved the problem of shortage of teachers and educational resources in colleges and universities. However, large-class teaching cannot pay attention to individuals, so the effectiveness of teachers' guidance cannot be realized naturally. In this case, the effectiveness of students' independent learning and cooperative learning will be greatly reduced. Our research results show that the grouping micro-video competition teaching mode can provide students with more activity space and opportunities to participate in them, as well as more frequent cooperation and interaction between students and teachers. It can be seen from the analysis results of each question type in the final examination that such teaching mode promotes students' ability to memorize, master, analyze and apply the basic knowledge. The new teaching mode has changed the way of learning of students. In the process of teachers' guidance and students' learning, both knowledge imparting and ability cultivation are emphasized. This teaching mode attaches great importance to the use of network and multimedia as well as to the multi-level realization means of learning cognition and diversified evaluation methods and the subjectivity of student evaluation. Students can also learn imperceptibly in the process of evaluating others.

Our research results show that there are significant differences on the scores of the objective questions and subjective questions by adopting the grouping micro-video competition teaching mode and traditional lecturing teaching mode, which indicates that grouping micro-video competition teaching mode is better than traditional lecturing teaching mode in large-class biochemistry course. This teaching model has the following four connotations: first, team-based learning; second, group competition; third, micro-video production; fourth, self-evaluation and other diversified evaluation with students as the subject. Team-based learning is conducive to the cultivation of students' independent learning, cooperation and mutual coordination. Micro-video production is conducive to the cultivation of students' hands-on ability and innovative spirit, while competition can stimulate students' interest and fight in learning and improve learning efficiency ${ }^{[4,5,8-12]}$. The main evaluation is to set up the main situation for the judgment, which makes the students have to meet the needs of the knowledge and ability preparation as the judgers through independent learning before the evaluation on others and learn imperceptibly in the process of evaluation of others ${ }^{[13,14]}$. The four connotations are involved in the whole process, which fully covers the individuals and learning time of students in the teaching process and truly reflects the student-centered learning philosophy.

Our statistical analysis of the scores of students in the same class namely the experimental class shows that although there is a statistically significant difference between the scores of objective questions in the experimental content and control content, there is no significant difference between the scores of subjective questions in the experimental content and the control content. The former indicates that the grouping micro-video competition teaching mode has a significant effect on promoting students' memorization and mastering of basic knowledge, but has no obvious effect on memorization and mastering of basic knowledge of other teaching contents. There is a significant difference on the scores of subjective questions between the experimental class and the control class, but there is no significant difference within the experimental class. Therefore, different from only promoting student memorization and mastery of experiment content, grouping micro-video competition teaching model has comprehensive effect on cultivating students' comprehensive analysis and the ability to apply knowledge, which not only promotes students' ability in the comprehensive analysis and using of the experiment content, but also promotes the same ability to learn other content. The cultivation of comprehensive analysis and knowledge application ability is lasting and permanent. Once this kind of ability is cultivated, it has the effect of drawing inferences from one example.

Although the grouping micro-video competition teaching mode has obvious advantages in the large-class teaching of biochemistry, there are some problems. For example, in the questionnaire survey, although students generally affirm the advantages of this teaching mode, they believe that this teaching mode is no more suitable for large-class teaching than the traditional lecture-based teaching mode, and it has no obvious advantages in improving students' attention in class. The reason for the former may be that students think that although the traditional lecturing teaching mode is not conducive to the acquisition of knowledge and the cultivation of various abilities of students, the teaching capacity may be larger, which may be related to the long-term acceptance of the conventional thinking of traditional lecturing teaching mode. As for the second question, it is mainly related to the fact that teachers are not proficient enough in the new teaching mode, thus having no significant effect in creating a better classroom atmosphere.

\section{CONCLUSION}

Grouping micro-video competition teaching mode is conducive to promote students' memorization and mastery of the experiment content, but it serves well in training students' comprehensive analysis and the ability to apply knowledge. It not only promotes students' ability in the comprehensive analysis and using of the experiment content, but also promotes the same ability in other learning content. Although grouping micro-video competition teaching mode is a very effective teaching mode, it still needs to be further improved.

\section{REFERENCES}

[1] Deng Yan, Liao Pinhu, On the Teaching and Practice of Teaching and Learning $[\mathrm{M}]$. Guangxi Science and Technology Publishing House, 2018. (In Chinese)

[2] Heller MP, King I. Team teaching: values and advantages [J]. Nurs Outlook, 1965, 13(10):50-51.

[3] Hellier S, Davidson L. Team teaching in nursing education [J]. J Contin Educ Nurs, 2018, 49(4):186-192.

[4] Gopalan C, Klann MC. The effect of flipped teaching combined with modified team-based learning on student performance in physiology [J]. Adv Physiol Educ, 2017, 41(3):363-367. 
[5] Jiang W, Tian Y, Chen J, Chen B. Team-, case-, lecture- and evidence-based learning [J]. Med Educ, 2017, 51(11):1172.

[6] Soyer E, Hogarth RM. Learning from experience in nonlinear environments: Evidence from a competition scenario [J]. Cogn Psychol, 2015, 81:48-73.

[7] Yokoyama T, Padmala S, Pessoa L. Reward learning and negative emotion during rapid attentional competition [J]. Front Psychol, 2015, 6:269.

[8] Lau KHV, Farooque P, Leydon G, Schwartz ML, Sadler RM, Moeller JJ. Using learning analytics to evaluate a video-based lecture series [J]. Med Teach, 2018, 40(1):91-98.

[9] Mota P, Carvalho N, Carvalho-Dias E, João Costa M, Correia-Pinto J, Lima E.Video-based surgical learning: improving trainee education and preparation forsurgery [J]. J Surg Educ, 2018,75(3):828-835
[10] Moore RM, Darby KH, Blake ME. A collaborative team teaching model for an MSW capstone course [J]. J Evid Inf Soc Work, 2016, 13(4):386-393.

[11] Berg RM, Toksvang LN, Jabbari R. Using an essay competition as an alternative tool for enhancing the "learning from learners" teaching approach [J]. Adv Physiol Educ, 2013, 37(3):264-265.

[12] Makhoul I, Motwani P, Schafer L, Arnaoutakis K, Mahmoud F, Safar M, Graves D, Mehta P, Govindarajan R, Hutchins L, Thrush C. Integrating collaborative learning and competition in a hematology/oncology training program [J]. J Cancer Educ, 2018, 33(1):186-192.

[13] Doménech-Betoret F. The educational situation quality model: recent advances. Front Psychol, 2018; 9: 328.

[14] Han Hongyan, Wang Peiyu, Chen Xinwang, Gao Xiyan, On Application and Exploration of Self-Evaluation and Mutual Evaluation in Practical Course of Manipulation of Acupuncture and Moxibustion [J]. Chinese Acupuncture and Moxibustion, 2016, 36(08):877-879.(In Chinese) 